\title{
Computational BIM for Building Envelope Sustainability Optimization
}

\author{
Yaik-Wah Lim ${ }^{1,2}$, Taki Eddine Seghier ${ }^{1}$, Muhamad Farhin Harun ${ }^{3}$, Mohd Hamdan Ahmad1, Azurah A. Samah ${ }^{3}$, and \\ Hairudin Abdul Majid ${ }^{3}$ \\ ${ }^{1}$ Faculty of Built Environment and Surveying, Universiti Teknologi Malaysia, Johor, Malaysia \\ ${ }^{2}$ Centre for the Study of Built Environment in the Malay World, Faculty of Built Environment and Surveying, Universiti Teknologi \\ Malaysia, Johor, Malaysia \\ ${ }^{3}$ School of Computing, Faculty of Engineering, Universiti Teknologi Malaysia, Johor, Malaysia
}

\begin{abstract}
Building envelope plays an important role to protect a building from external climatic factors while providing a comfortable indoor environment. However, the choices of construction materials, opening sizes, and glazing types for optimized sustainability performance require discrete analyses and decision-making processes. Thereby this study explores the use of computational building information modelling (BIM) to automate the process of design decision-making for building envelope sustainability optimization. A BIM tool (Revit), a visual programming tool (Dynamo) and multi objective optimization algorithm were integrated to create a computational BIM-based optimization model for building envelope overall thermal transfer value (OTTV) and construction cost. The proposed model was validated through a test case; the results showed that the optimized design achieved $44.78 \%$ reduction in OTTV but $19.64 \%$ increment in construction cost compared to the original design. The newly developed computational BIM optimization model can improve the level of automation in design process for sustainability.
\end{abstract}

\section{Introduction}

Building envelope is important to protect the indoor environment from outdoor climatic forces. In tropical region, where the climate is hot and humid throughout the year, protection against solar heat gain is critical to achieve energy saving and sustainable building performance. Therefore, the building envelope design, opening sizes and materials should minimize the outdoor solar heat gain to reduce cooling load while providing comfortable indoor spaces $[1,2]$.

Approaches to reduce solar heat gain through building envelope include increasing thermal insulation, reducing window sizes as well as using building materials and glazing that have low thermal transmittance (U-value) $[3,4]$. Nevertheless, the choices of building material will affect the construction cost. Thus the trade-off between the thermal performance and cost is needed to derive optimum solutions [5]. Different analyses are required to evaluate the performances, and some of these processes are disjointed [6].

Building information modelling (BIM) allows a complicated building to be modelled digitally with various information including the thermal properties and cost. The data can be extracted through programming script for optimization using algorithm [7,8]. Thereby this study explores the use of computational building information modelling (BIM) to automate the process of design decision-making for building envelope sustainability optimization.

\subsection{Building envelope performance}

The Overall Thermal Transfer Value (OTTV) is commonly used as a control for non-residential building envelope design. According to Malaysia Standard (MS) 1525:2014 [4], the OTTV of the building envelope for a building which has a total air-conditioned area exceeding $1000 \mathrm{~m}^{2}$ should not exceed $50 \mathrm{~W} / \mathrm{m}^{2}$. The Equation 1 to calculate OTTV is as shown below:

$$
\begin{aligned}
\text { OTTVi }= & 15 \alpha(1-W W R) U w+6(W W W R) U f(1) \\
& +\left(194^{*} O F^{*} W W R^{*} S C\right)
\end{aligned}
$$

Where,

WWR: The window-to-gross exterior wall area ratio for the orientation under consideration

$\alpha \quad: \quad$ The solar absorptivity of the opaque wall;

Uw : The thermal transmittance of opaque wall $\left(\mathrm{W} / \mathrm{m}^{2} \mathrm{~K}\right)$;

Uf : The thermal transmittance of fenestration system $\left(\mathrm{W} / \mathrm{m}^{2} \mathrm{~K}\right)$;

OF : The solar orientation factor; as in MS1525

SC : The shading coefficient of the fenestration system

The OTTV is affected by the choice of building envelope materials including wall and window types. Furthermore, the selection of building envelope materials 
will also affect the construction cost. Consequently, there is always a conflict in achieving lower OTTV and construction cost saving. In this study, construction cost (Equation 2) was selected as the second objective function for the optimization.

$$
C=C \text { win }^{*} N \text { win }+C w^{*} A w
$$

Where,

Cwin: Cost of window per unit;

Nwin: Number of window units;

$\mathrm{Cw}$ : Cost of wall per $\mathrm{m}^{2}$;

Aw : Area of wall

\subsection{Computational BIM}

According to the U.S. National BIM Standard in 2007, $\mathrm{BIM}$ is " $a$ digital representation of physical and functional characteristics of a facility and a shared knowledge resource for information about a facility forming a reliable basis for decisions during its lifecycle" $[9,10]$. On the other hand, Jeong et al. [11] defines $\mathrm{BIM}$ as " a verb or adjective phrase to describe tools, processes, and technologies that are facilitated by digital machine-readable documentation about a building, its performance, its planning, its construction, and later its operation". Thus BIM is not just a software; in fact, it is a process that runs through software.

Apart from the development of BIM, building practitioners have become more interested in visual programming tools since the last decade. These tools, such as Grasshopper, Dynamo and Marionette, can create customized and flexible form-generating algorithms [12]. Visual programming language (VPL) can be integrated with BIM to manipulate the embedded information within the model. BIM-VPL integration opens up the possibility to automate many tasks in BIM design workflow.

Autodesk has integrated Dynamo, which is an open source visual programming tool, to improve building design process and workflows in a BIM authoring tool Revit, so that designers can construct programmatic relationship using a graphical user interface (GUI) instead of 'code' from scratch. Dynamo platform is inspired by previous visual programing tools such as Grasshopper; its capability in manipulating the parameters of Revit added an extra level of associativity and created new opportunities for cross-platform and cross-discipline collaboration [13].

Previous studies have applied visual programming tools for building performance analyses such as energy and daylighting optimization [14], structural analysis [15] and acoustical analysis [16]. However, there is still lack of comprehensive VPL-based model or workflow for building sustainability analyses.

Kensek [12] argued that visual programming tool can support sustainable design studies in the early stages of building design. Konis et al. [17] developed a framework for building passive performance optimization for early design stage, which implements a simulation-based parametric modelling workflow to optimize several aspects of building envelop configuration.

\subsection{Multi objective optimization}

Multi objective optimization (MOO) has more complex implementations and constraints compared to single objective optimization. There are many MOO algorithms which has different types of approach, and most of them require at least two conflicting objective functions to operate $[18,19]$.

In some case of optimization, best solution can be skipped during crossover and mutation processes, hence producing a weaker offspring. The concept of elitism is used in MOO to overcome the problem. Elitism is the mechanism used to preserve good solution in every generation, thus giving better performance than nonelitism algorithm [19].

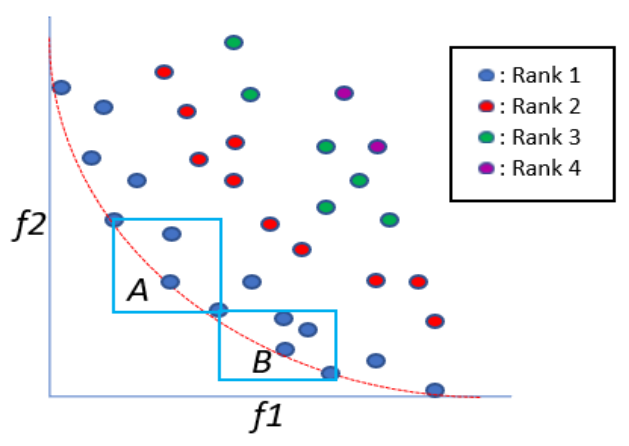

Fig. 1. NSGA-II output

An elitism MOO algorithm called Non-Dominated Sorting Genetic Algorithm II (NSGA-II) was developed by Deb et al. [20]. It is easy to apply and uses Genetic Algorithm (GA) mechanism for the data manipulation which is a perfect fit for combinatorial problems. NSGAII is different from GA in term of data selection; GA selects data which has the best objective value while NSGA-II uses non-dominated sorting and crowding distance. These mechanisms will produce a set of solution which called optimal Pareto solution, as shown in Figure 1 when it is plotted in a graph. From the Pareto solution, the user can find optimal trade-off between the variables involved.

\section{Computational BIM Optimization Model}

To explore the implementation of computational BIM to optimize building envelope sustainability performance, a conceptual model which integrates a BIM tool (Revit), a visual programming tool (Dynamo) and MOO in Matlab to optimize OTTV and construction cost has been formulated (Figure 2). There are four main components in this model, namely BIM model preparation, Dynamo scripts for data management, Data hosting in Excel, and OTTV-cost optimization in MATLAB. 


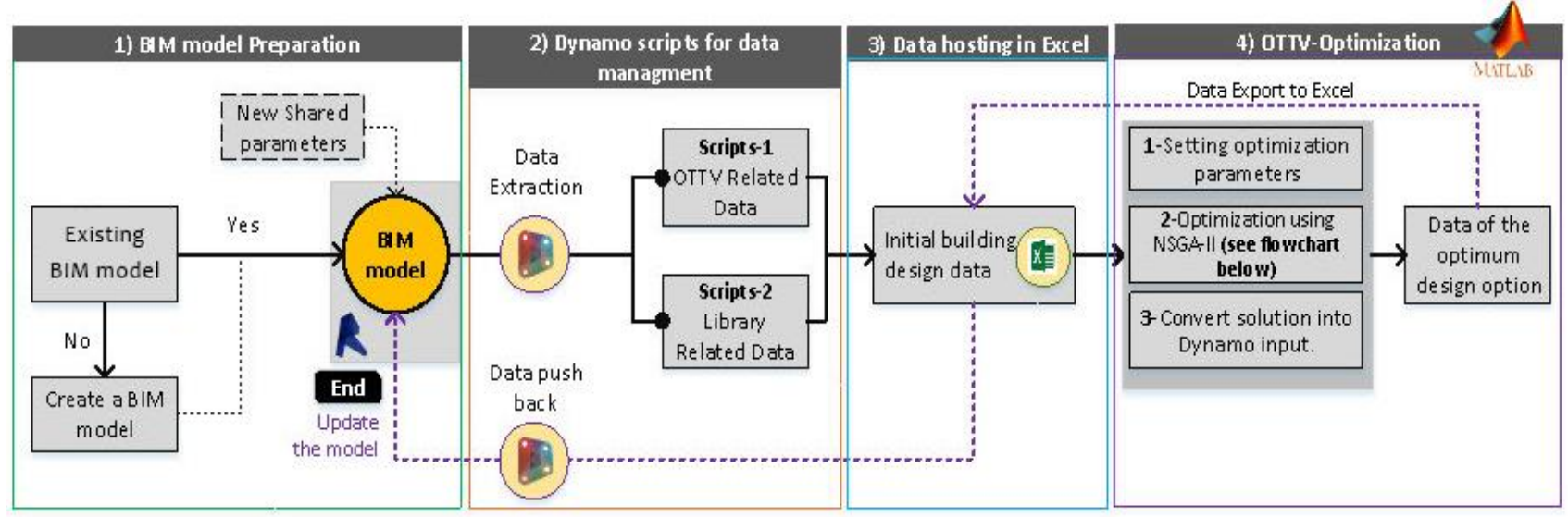

Fig. 2. Computational BIM-based OTTV-cost optimization model

Firstly, a building has to be modelled in Revit; if there is an existing Revit model, it can be directly adopted. However, new shared parameters have to be inputted into the Revit model including all the variables required to calculate OTTV (Equation 1) and construction cost (Equation 2)

Then, Dynamo scripts are developed to extract data from the Revit model; Scripts-1 is used for OTTV and cost-related data extraction such as window area, wall area, u-value, solar absorptivity, orientation, construction cost, etc. Scripts-2 is used for library related data extraction; all wall and window types including their thermal properties and costs in the Revit model are extracted to generate combinations for optimization purpose. The extracted data are hosted in Excel; the entire process of data extraction and hosting is automated by the Dynamo scripts.

The data in Excel are called by MATLAB programming for MOO. Binary NSGA-II is used; the binary form formulates the combination of materials that produce specific OTTV and cost. Hence, the objective is to find the best combination that produces optimum OTTV and cost. The population is the combination of wall and window identifications (IDs) used in the construction of the building envelope. More combination means longer string and more complex OTTV calculation. Besides that, longer string also produces more new children. In addition, there is a concern of more dataset of materials in the library which increases the number of possible combinations of the data.

Crossover process is done by exchanging bits between two data (parents) to create two new data (children). NSGA-II merges both of parents and children to create new and larger population set and the non-dominance concept is used to find the better solution. Both wall and window sections are involved in the crossover process. If both wall and window have only one type each, crossover process is skipped. Interchange of the wall with window bit and vice versa are prevented as both value has no connection and later can be treated as a mutation. Besides, bit-flip mutation is used to alter the chosen data. Each material in wall and window is a bit-flip with the library dataset in the database.
The optimization experiment begins with the random selection of various material combinations. The corresponding OTTV and cost functions are then calculated. The data produced is known as parent population, P. Initial population than undergo selection, crossover, and mutation. The new population is produced known as children population, C. Final population, $\mathrm{P}^{\prime}$ is generated by combining $\mathrm{P}$ and $\mathrm{C}$. $\mathrm{P}$ ' then is sorted by non-dominated sorting and calculated the crowding distance for all data in P'. Trimming process is to select population to its original size where in this case is the size of $\mathrm{P}$. The process is repeated until stopping criteria are met (Figure 3 ).

The optimum solution is then identified and extracted with its materials combination. This combination needs to be validated using Revit to visualize the physical change using the new optimum design solutions. Hence, as shown in Figure 2, the optimized data is exported to Excel and then pushed back to Revit automatically using Dynamo script.

Finally, the data push back using Dynamo allows the Revit model to be updated with the optimized design for visualization and checking. The use of computational $\mathrm{BIM}$, which integrates BIM with visual programming and MOO algorithm, increases the level of automation for the process of evaluating the building envelope OTTV and cost as well as finding the optimum design solution.

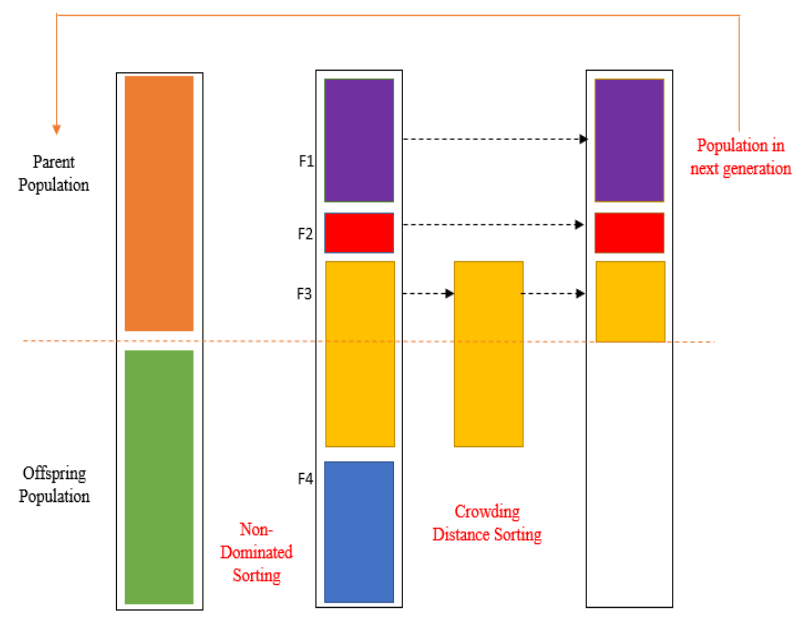

Fig. 3. NSGA-II Process 


\section{Test Case}

To validate the proposed computational BIM-based OTTV-cost optimization model, a test case was developed by using an existing non-residential building located in Johor Bahru, Malaysia with latitude $1.56^{\circ} \mathrm{N}$ and longitude $103.64^{\circ} \mathrm{E}$ (as shown in Figure 4). The building is within the tropical region, with façade facing north-east, south-east, south-west and north-west. It was modelled in Revit including all the required parameters for OTTV and construction cost calculations.

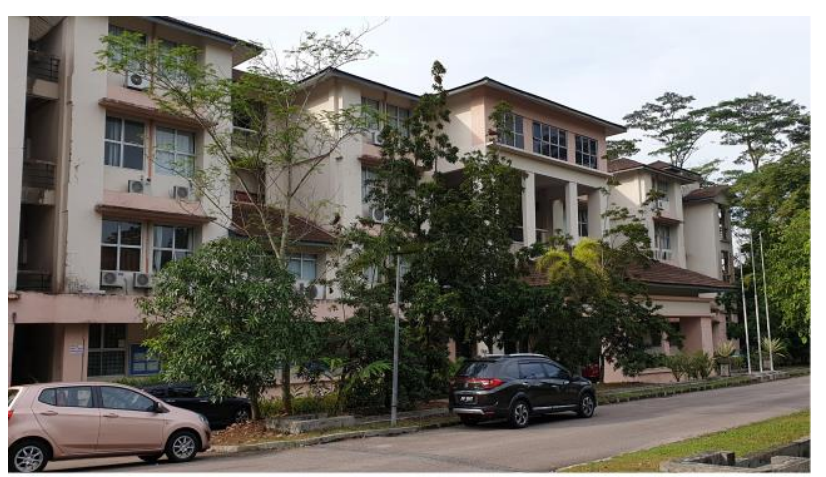

(a)

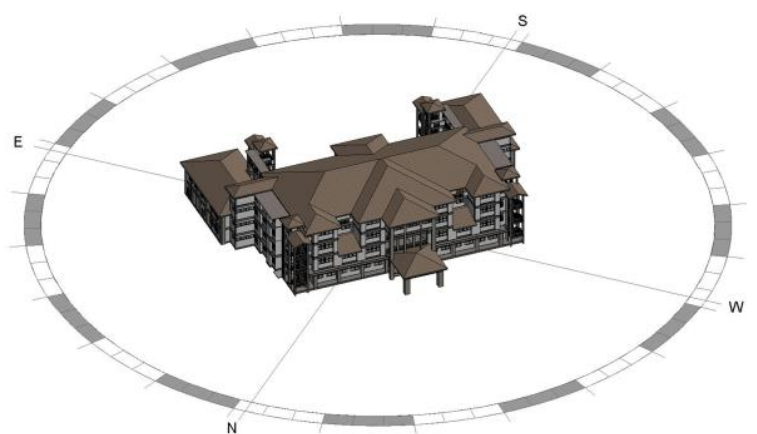

(b)

Fig. 4. Case study building: (a) Actual building; (b) BIM model in Revit

Table 1. Comparison of original and optimized design

\begin{tabular}{|c|c|c|c|c|c|c|}
\hline \multirow[b]{2}{*}{ 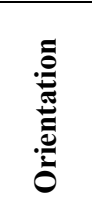 } & \multicolumn{3}{|c|}{ OTTV } & \multicolumn{3}{|c|}{ Construction Cost } \\
\hline & 焉 & 㺼 & 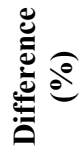 & 焉 & 兽 & 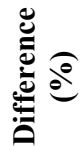 \\
\hline $\begin{array}{c}\text { North- } \\
\text { East }\end{array}$ & $\begin{array}{l}\text { fे } \\
\stackrel{\sigma}{f}\end{array}$ & 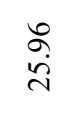 & $\frac{n}{\mathfrak{r}}$ & 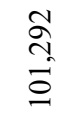 & $\begin{array}{l}\infty \\
\infty \\
\infty \\
=\end{array}$ & $\frac{\hat{N}}{+}$ \\
\hline $\begin{array}{c}\text { South- } \\
\text { East }\end{array}$ & i̊ & $\frac{\mathfrak{n}}{\dot{\sigma}}$ & $\begin{array}{l}\stackrel{9}{\vec{n}} \\
\stackrel{\vec{n}}{1}\end{array}$ & $\begin{array}{l}\infty \\
\pm \\
\pm\end{array}$ & 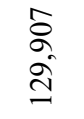 & $\frac{\hat{r}}{\dot{m}}$ \\
\hline
\end{tabular}

\begin{tabular}{|c|c|c|c|c|c|c|}
\hline $\begin{array}{c}\text { South- } \\
\text { West }\end{array}$ & $\begin{array}{l}\infty \\
\infty \\
\infty\end{array}$ & 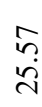 & $\begin{array}{l}\underset{\forall}{\forall} \\
\underset{+}{+}\end{array}$ & $\begin{array}{l}\tilde{N} \\
\tilde{n} \\
\infty \\
0\end{array}$ & 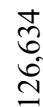 & $\begin{array}{l}\hat{b} \\
\dot{0} \\
+\end{array}$ \\
\hline $\begin{array}{l}\text { North- } \\
\text { West }\end{array}$ & $\frac{7}{\hat{b}}$ & ले & กี & $\begin{array}{l}\stackrel{\infty}{f} \\
\underset{\Xi}{\Xi}\end{array}$ & $\begin{array}{l}\infty \\
\stackrel{\infty}{b} \\
\dot{y} \\
\dot{J}\end{array}$ & $\begin{array}{l}\stackrel{P}{1} \\
\stackrel{\oplus}{+}\end{array}$ \\
\hline Overall & $\begin{array}{l}\text { oे } \\
\dot{0} \\
n\end{array}$ & ò & $\begin{array}{l}\infty \\
\stackrel{\infty}{+} \\
\forall\end{array}$ & $\begin{array}{l}\vec{\infty} \\
+ \\
\sim \\
\tilde{\sigma}\end{array}$ & $\begin{array}{l}\bar{\delta} \\
\text { ते } \\
\text { n. }\end{array}$ & 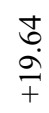 \\
\hline
\end{tabular}

Table 1 shows the comparison of the OTTV and construction cost between the original design and the optimized design using the computational BIM-based model. The results indicate that the OTTVs for envelopes of all the four orientations had been successfully lowered; with the highest reduction of $50.32 \%$ for north-west façade. Whereas, the construction costs of the envelopes were increased, with the highest increment $(30.70 \%)$ for north-west façade as well.

After the optimization, the overall OTTV was significantly decreased from $56.09 \mathrm{~W} / \mathrm{m}^{2}$ to $30.97 \mathrm{~W} / \mathrm{m}^{2}$ $(-44.78 \%)$ while the overall construction cost was reasonably increased from RM435,481 to RM521,021 (19.64\%). Figure 5 shows the comparison between the original and optimized building façade design (north-west) as modelled in Revit. The building façade was automatically updated when the data were pushed back to Revit by the Dynamo script, however further checking was needed to assure no clashing of window with another window or other building components due to the change of window area (WWR).
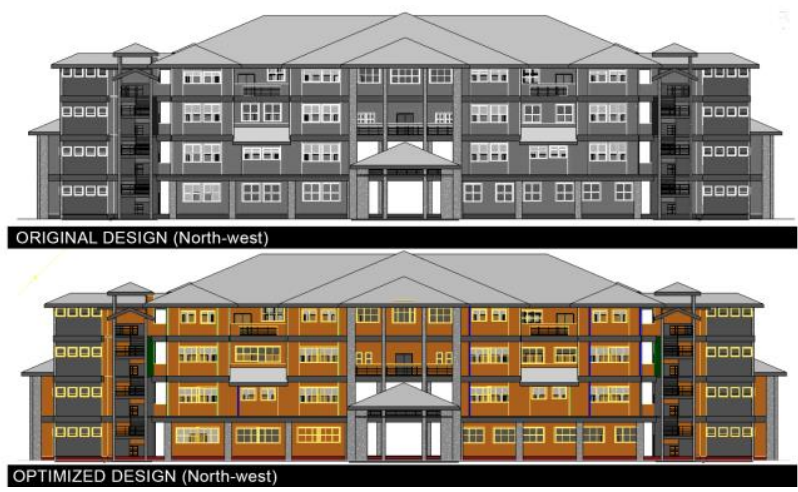

Fig. 5. Original and optimized design of north-west façade

The OTTV and construction cost as outputs from the MATLAB programming were compared with manual calculations as shown in Table 2. The comparison shows that the MATLAB outputs are identical with the manual calculations thus giving reliable results. Therefore, the proposed computational BIM-based model and test case had successfully optimized the design of the selected building by lowering the OTTV to below $50 \mathrm{~W} / \mathrm{m}^{2}$ (as required in MS 1525:2014) with accurate results. 
Table 2. Comparison of MATLAB output and manual calculation

\begin{tabular}{|c|c|c|c|c|}
\hline \multirow{2}{*}{ Orientation } & \multicolumn{2}{|c|}{ MATLAB Output } & \multicolumn{2}{c|}{ Manual Calculation } \\
\cline { 2 - 5 } & $\begin{array}{c}\text { OTTV } \\
\left(\mathbf{W} / \mathbf{m}^{2}\right)\end{array}$ & $\begin{array}{c}\text { Cost } \\
(\mathbf{R M )}\end{array}$ & $\begin{array}{c}\text { OTTV } \\
\mathbf{( W / m}^{2} \mathbf{)}\end{array}$ & $\begin{array}{c}\text { Cost } \\
(\mathbf{R M )}\end{array}$ \\
\hline North-East & 25.960 & 118,782 & 25.960 & 118,782 \\
\hline South-East & 41.650 & 129,907 & 41.648 & 129,907 \\
\hline South-West & 25.570 & 126,634 & 25.570 & 126,634 \\
\hline North-West & 31.390 & 145,698 & 31.386 & 145,698 \\
\hline Overall & 30.970 & 521,021 & 30.970 & 521,021 \\
\hline
\end{tabular}

\section{Discussion and Conclusion}

Decision-making in sustainable building envelope design needs to meet various discrete performance requirements by conducting disjointed evaluation processes, which will be very time and cost consuming. Thereby a higher level of automation in the design decision-making and optimization is needed to facilitate the building industry to achieve sustainability.

This research has explored the use of computational BIM, which integrates BIM with visual programming and MOO algorithm, as a potential solution to increase the level of automation in building envelope optimization. As a result, a new computational BIM-based model to optimize building envelope OTTV and construction cost was developed. It was further validated through a test case, which has proven significant reduction of OTTV is achievable with reasonably higher construction cost investment.

This study was conducted with Malaysia's context; the OTTV calculation and requirement were based on MS 1525:2014 that has consideration of tropical region near the Equator; the construction cost was based on the Malaysia's construction industry. Nevertheless, the proposed conceptual model is applicable to any other climatic and economic contexts.

Though the newly proposed computational BIMbased optimization model only includes OTTV and construction cost as the objective functions, using the similar method, it can be further developed as a comprehensive integrated computational BIM-based optimization tool for different design variables and objective functions.

\section{Acknowledgement}

The authors would like to acknowledge the research funding by Universiti Teknologi Malaysia (UTM) and Ministry of Education (MOE), Malaysia through Research University Grant (GUP), project no. 13H40, titled "Retrofitting Building Information Modelling (RBIM) for Sustainable Buildings".

\section{References}

1. Y.W. Lim, Dynamic Daylight and Solar Control in Tropical Climate. American Journal of Applied Sciences, 11(10), 1766-1772 (2014)

2. Y.W. Lim, Indoor Environmental Comfort in Malaysian Urban Housing. American Journal of Environmental Science, 9(5), 431-438 (2013)

3. Green Building Index (GBI), GBI Assessment Criteria (2013)

4. Department of Standards Malaysia, Malaysian Standard 1525:2014 - Energy efficiency and use of renewable energy for non-residential buildings Code of practice, $2^{\text {nd }}$ revision (2014)

5. Y.W. Lim, H.A. Majid, A.A. Samah, M.H. Ahmad, D.R. Ossen, M.F. Harun, F. Shahsavari, BIM and Genetic Algorithm optimization for sustainable building envelope design. International Journal of Sustainable Development and Planning, 13(1), 151159 (2018)

6. Y.W. Lim, F. Shahsavari, N. Fazlenawati, D.R. Ossen, M.H. Ahmad, Developing a BIM-based process-driven decision-making framework for sustainable building envelope design in the tropics. Proceedings of Building Information Modelling (BIM) in Design, Construction and Operations, 9-11 September, Bristol, UK, 531-542 (2015)

7. S. Oh, Y. Kim, C. Park, I. Kim, Process-driven BIMbased optimal design using integration of EnergyPlus, Genetic Algorithm, and Pareto Optimality, in Proceedings of Building Simulation, 14-16, (2011)

8. Y.W. Lim, Building Information Modeling for Indoor Environmental Performance Analysis. American Journal of Environmental Sciences, 11(2), 55-61 (2011)

9. P.C. Suermann, R.R.A. Issa, Evaluating industry perceptions of building information modeling (BIM) impact on construction, Electronic Journal of Information Technology in Construction, 14, 574594 (2009)

10. G. Aranda-Mena, J. Crawford, A. Chevez, T. Froese, Building information modelling demystified: does it make business sense to adopt BIM?, International Journal of Managing Projects in Business, 2(3), 419434 (2009)

11. Y.-S. Jeong, C.M. Eastman, R. Sacks, I. Kaner, Benchmark tests for BIM data exchanges of precast concrete, Automation in Construction, 18(4), 469484 (2009)

12. K. Kensek, Visual programming for building information modeling: energy and shading analysis case studies, Journal of Green Building, 10(4), 28-43 (2015)

13. K.M. Kensek, D.E. Noble, (2014). Building Information Modeling: BIM in Current and Future Practice. Journal of Chemical Information and Modeling, 53 (2014)

14. M.R. Asl, A. Stoupine, S. Zarrinmehr, W. Yan, Optimo: A BIM-based Multi-Objective Optimization Tool Utilizing Visual Programming for High Performance, In eCAADe (2011)

15. M. Makris, D. Gerber, A. Carlson, D. Noble, Informing Design through Parametric Integrated Structural Simulation. In eCAADe, 1, 69-77 (2013) 
16. Acoustamo Released. Retrieved February 17, 2017, from https://andreaarch.wordpress.com/

17. K. Konis, A. Gamas, K. Kensek, Passive performance and building form: An optimization framework for early-stage design support, Solar Energy, 125, 161-179 (2016)

18. M.F. Harun, A.A Samah, H.A. Majid, Y. Yusoff, Y.W. Lim, Optimization of Green Building Design to Achieve Green Building Index (GBI) Using Genetic Algorithm (GA). In Student Project
Conference (ICT-ISPC), 6th ICT International, 6, 36 (2017)

19. V.L. Vachhani, V.K. Dabhi, H.B. Prajapati, Survey of multi objective evolutionary algorithms. In IEEE International Conference on Circuit, Power and Computing Technologies, ICCPCT (2015)

20. K. Deb, S. Pratab, S. Agarwal, T. Meyarivan, A Fast and Elitist Multiobjective Genetic Algorithm: NGSA-II. IEEE Transactions on Evolutionary Computing, 6(2), 182-197 (2002) 